\title{
Refractory Chemotherapy-Induced Nausea and Vomiting
}

National Cancer Institute

\section{Source}

National Cancer Institute. Refractory Chemotherapy-Induced Nausea and Vomiting. NCI Thesaurus. Code C147045.

Chemotherapy-induced nausea and vomiting that does not respond to treatment. 